\title{
Orofacial granulomatosis: insights from an immunohistochemical evaluation
}

\author{
Patrícia C Caldeira, Giovanna R Souto, Maria Cássia F de Aguiar, Maria Auxiliadora V do Carmo \\ Department of Oral Pathology and Surgery, School of Dentistry, Universidade Federal de Minas Gerais, Belo Horizonte, \\ Brazil
}

Correspondence: Patrícia C Caldeira. Address: Universidade Federal de Minas Gerais. Faculdade de Odontologia, sala 3201. Av. Antônio Carlos, 6627, Pampulha. CEP 31.270-901, Belo Horizonte, MG, Brasil. E-mail:

pat_caldeira@yahoo.com.br

Received: February 24, 2014

Accepted: April 25, 2014

Online Published: April 29, 2014

DOI : $10.5430 /$ crcp.v1n2p71

URL: http://dx.doi.org/10.5430/crcp.v1n2p71

\section{Abstract}

Objective: The aim of this paper was to report a case of orofacial granulomatosis, with immunohistochemical evaluation of some inflammatory cells that would be involved on its etiopathogenesis.

Methods: The specimen was collected through biopsy for diagnostic proposal and was further submitted to immunohistochemistry for CD3, CD20, S-100, D2-40, and AE1/AE3. Immunohistochemical analysis was performed in inflammatory cells in granulomatous nodules and through the oral mucosa.

Results: In the granulomas, CD3+ cells were the main component of inflammatory cells. S-100+ cells were seen diffusely distributed. CD20+ cells were observed in a lower amount than CD3+ and S-100+. D2-40 staining evidenced some large lymphatic vessels, which were surrounded by inflammatory cells. Besides the granulomas, an intense and diffuse inflammatory infiltrate was seen in connective tissue, immediately below the epithelium with a large number of CD3+ cells in intimate contact. A disorganization of the basal layer of epithelium was also present. AE1/AE3 was positive only in the keratinocytes. S-100+ cells were numerous in the connective tissue, and infiltrating the epithelium. CD20+ cells were observed in a lower number than $\mathrm{CD} 3+$ and $\mathrm{S}-100+$, mainly located in a deeper region of the connective tissue.

Conclusions: Dendritic cells and T lymphocytes were the major components of inflammatory infiltrate in oral mucosa and granulomatous nodules. The observed epithelial disorganization was quite similar to that of lichen planus. The findings corroborate to a cell-mediated immunological background of orofacial granulomatosis.

\section{Key words}

Orofacial granulomatosis, Cheilitis granulomatosa, Immunohistochemistry

\section{I ntroduction}

Orofacial granulomatosis (OFG) is an uncommon and controversial immunologically mediated disease, first described by Wiesenfeld and colleagues in $1985^{[1]}$. It usually presents as an asymptomatic non-tender swelling of one or both lips, which can be a recurrent, permanent or progressive condition ${ }^{[2-4]}$. When arising exclusively in the lips, the condition is also called cheilitis granulomatosa ${ }^{[3,5,6]}$. Nevertheless, the swelling may be accompanied by a spectrum of other orofacial features like oral ulceration, gingival overgrowth, and a cobblestone appearance of the buccal mucosa ${ }^{[2,7]}$. When 
associated with fissured tongue and facial nerve palsy, it is named Melkersson-Rosental syndrome ${ }^{[3]}$. Moreover, OFG may represent the earliest manifestation of Crohn's disease, a granulomatous condition that can affect any part of the gastrointestinal tract ${ }^{[4,5,7-9]}$.

The prevalence of OFG is thought to be $0.8 \%{ }^{[10]}$ and it seems to have an equal prevalence in man and woman, in their 3rd and 4 th decades of life ${ }^{[2,10]}$, mainly in patients with clinical atopy.

The histopathological examination of OFG reveals non-caseating granulomas consisted of epithelioid histiocytes surrounded by lymphocytes, with or without multinucleated giant cells ${ }^{[2]}$. In addition, edema, dilated lymphatic and blood vessels, and perivascular lymphocytic infiltration are observed ${ }^{[2,10]}$. Of notice, the absence of granulomas does not exclude OFG diagnosis, and a non-specific inflammatory infiltrate may be the single finding ${ }^{[2,10]}$.

The etiopathogenesis of OFG is unknown, and genetics, allergy to food or dental materials, and infection have been mentioned as possible causes, and the immunological response seems to play an important role ${ }^{[3,9,10]}$. It is probable that food substances would evoke a delayed type hypersensitivity reaction, but it is to be clarified whether these antigenic irritants are causative or exacerbative agents ${ }^{[9,11,12]}$. Moreover, the stimulating antigen seems to vary from patient to patient ${ }^{[9]}$.

The clinical outcome of OFG patients remains unpredictable, but spontaneous remission of lesions is rare, and the aims of therapy are to lessen or even resolve the swellings ${ }^{[2,9]}$. Even though, considering the uncertain etiology of OFG, rational therapy is still not available ${ }^{[9]}$. To date, corticosteroids are considered the mainstay of therapy, which can be topical, systemic, intralesional, or a combined approach ${ }^{[2-4,9]}$.

The purpose of this paper was to report a case of OFG, with immunohistochemical evaluation of some inflammatory cells that would be involved on its etiopathogenesis.

\section{Case presentation}

A 20-year-old woman presented to Oral Pathology Clinic for evaluation of an asymptomatic and recurrent erythematous swelling of the upper lip, which appeared 15 days prior to the appointment. The medical history revealed constipation and Hashimoto's disease, for which she was taking appropriate medication. She also reported allergy to anti-inflammatory drugs. On examination, an ill-defined discrete swelling in the left side of upper lip was noted (see Figure 1). The mucosa was soft and painless on palpation, without color alteration. The patient did not have fissured tongue.

Figure 1. Clinical presentation: a discrete swelling in the left side of the upper lip

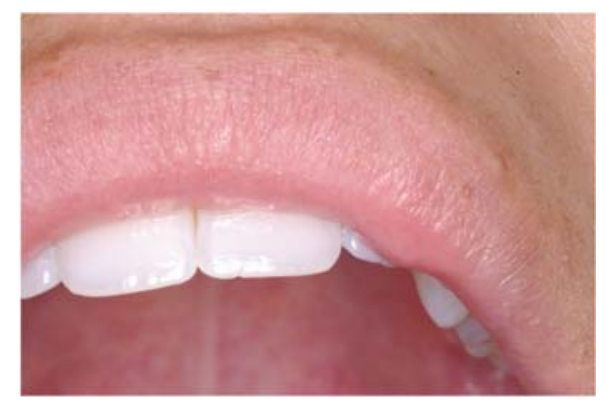

One week later, the clinical presentation remained unchanged. Hematological examination revealed no alteration, and tests for syphilis, HIV, tuberculosis, and sarcoidosis proved negative. Therefore, an incisional biopsy was performed. Based on microscopic findings, a diagnosis of OFG was done and the patient was referred to a physician for investigation of Crohn's disease. At that time, no alteration was detected. At the follow-up appointments, the patient reported recurrent swelling episodes that were triggered by alcoholic beverage and soft drinks. Of note, after two years, she developed lactose intolerance. 


\section{Microscopic evaluation and immunohistochemistry}

An epithelial coverage sustained by a connective tissue was observed. An intense and diffuse inflammatory infiltrate, mainly composed of lymphocytes, was present immediately below the epithelium (see Figure 2A), which presented exocytosis. A disorganization of the basal layer of epithelium was evident in focal areas (see Figure 2B), somehow resembling lichen planus features.

Figure 2. Microscopic findings; hematoxylin and eosin: (A) mucosal fragment showing formation of well-defined granulomas in the corium; 50×. (B) Non-caseating granulomas; 100×. (C) Connective tissue immediately below epithelium showing diffuse and intense inflammation; 100×. (D) Basal layer of epithelium was disorganized, resembling lichen planus. Inflammatory cells are mainly lymphocytes. Note exocytosis; $400 \times$.
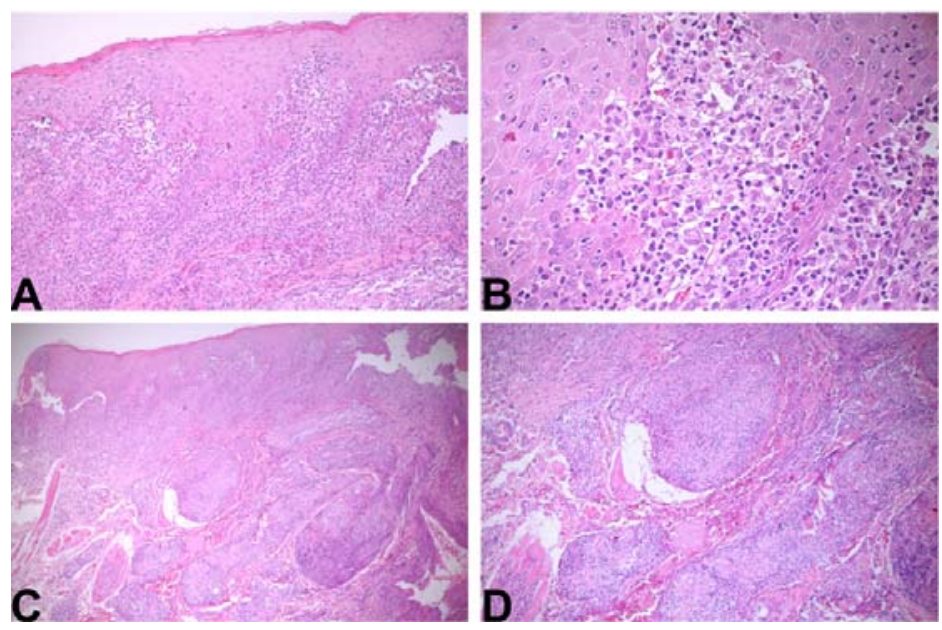

The microscopic evaluation of the lamina propria revealed granulomatous nodules, characterized by round structures composed of inflammatory cells and vessels, intermixed with connective tissue (see Figure 2C, 2D). No multinucleated giant cells or foreign material was seen and areas with diffusely distributed inflammatory cells could be noticed.

Investigation for pathogens was performed, but PAS, Ziehl-Neelsen, and Grocott-Gomori stains were negative, ruling out a possible infectious etiology.

So, to better understand the composition of inflammatory cells in order to add more reliable information about OFG, immunohistochemistry for AE1/AE3+, CD3+, CD20+, S-100+, and D2-40+ was done (see the Table). Briefly, $3 \mu \mathrm{m}$ sections were dewaxed in xylene and hydrated with graded ethanol. Antigen retrieval was performed. Endogenous peroxidase was blocked with a 10v solution of $\mathrm{H} 2 \mathrm{O} 2$. Slides were incubated with primary antibodies for 1 hour at room temperature. Detection was undertaken with LSAB+ system (Dako Cytomation, Carpinteria, CA, EUA, code K0690). Reactions were revealed with DAB chromogenic solution (Dako Cytomation, Carpinteria, CA, EUA, code K3468). Mayer's hematoxylin was used for counterstaining.

Table. Immunohistochemistry specifications

\begin{tabular}{llll}
\hline Primary antibody & Clone/manufacturer & Antigen retrieval & Dilution \\
\hline \multirow{2}{*}{ AE1/AE3 } & AE1/AE3, Dako Cytomation, Carpinteria, & Citric acid, pH 6.0, water bath $96^{\circ} \mathrm{C}, 30$ & $1: 100$ \\
& CA, code M3515 & minutes & TRIS-EDTA, pH 9.0, water bath $96^{\circ} \mathrm{C}, 30$ \\
CD3 & F7.2.38, Dako Cytomation, Denmark, code & minutes & $1: 200$ \\
& M7254 & Citric acid, pH 6.0, water bath $96^{\circ} \mathrm{C}, 30$ & $1: 200$ \\
CD20cy & L26, Dako Cytomation, Denmark, code & minutes & $1: 500$ \\
& M0755 & No treatment required & $1: 100$ \\
S100 & Polyclonal, Dako Cytomation, Denmark, & Citric acid, pH 6.0, water bath $96^{\circ} \mathrm{C}, 30$ & \\
\hline
\end{tabular}

AE1/AE3 was positive only in the keratinocytes, as expected. CD3+, CD20+, and S-100+ cells could be observed in the diffuse inflammatory infiltrate below the epithelium. A large number of $\mathrm{CD} 3+$ cells were visualized, mainly in the Published by Sciedu Press 
connective tissue in intimate contact with epithelium (see Figure 3A). These cells could be seen intermixing keratinocytes as well (see Figure 3B). S-100+ dendritic cells were notably numerous in the connective tissue, and infiltrating the epithelium (see Figure 3C). Finally, CD20+ cells were observed, but in a much lower number. These cells were mainly located in a deeper region of the connective tissue, with few cells infiltrating epithelium (see Figure 3D).

Figure 3. Immunohistochemical findings in mucosal area; streptavidin-biotin: (A) CD3+ lymphocytes comprised the majority of cells; 100×. (B) Numerous CD3+ cells in the epithelium-connective tissue junction and intermixing keratinocytes; $400 \times$. (C) Numerous $\mathrm{S}-100+$ cells were seen in the connective tissue and intermixing keratinocytes; 200×. (D) $\mathrm{CD} 20+$ cells were less numerous and were observed in a deeper localization within the connective tissue; $100 \times$.

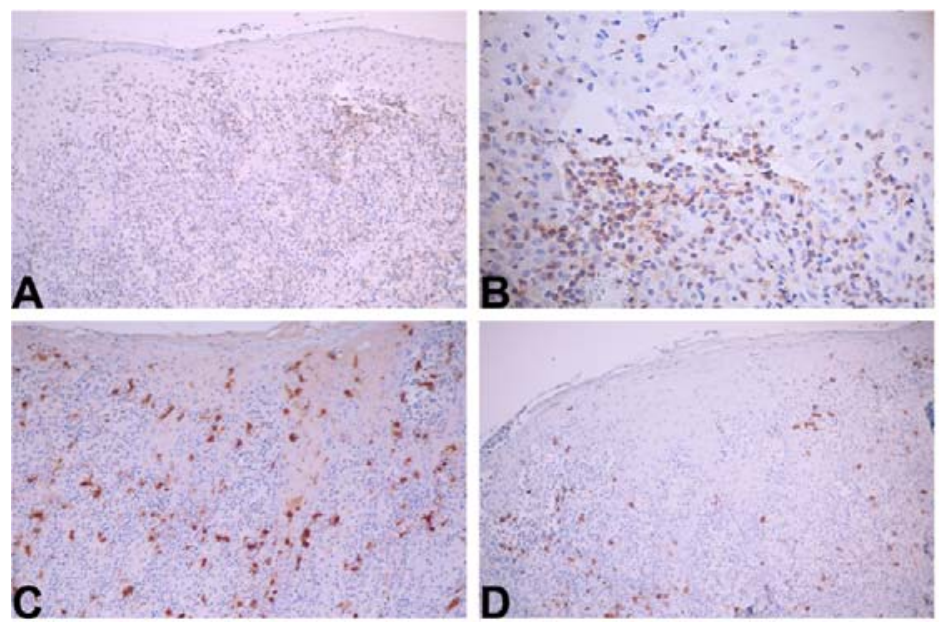

In the granulomas, the majority of the inflammatory cells were represented by CD3+ lymphocytes (see Figure 4A). S-100+ cells were seen diffusely distributed throughout the granulomas (see Figure 4B). CD20+ cells were observed in a lower amount than CD3+ and S-100+ (see Figure 4C). D2-40 staining also evidenced some large lymphatic vessels within the granulomas (see Figure 4D).

Figure 4. Immunohistochemical findings in granuloma; streptavidin-biotin, 400×: (A) $\mathrm{CD} 3+$ lymphocytes composed the majority of inflammatory cells. (B) S-100+ cells were noted throughout the granuloma. (C) $\mathrm{CD} 20+$ cells were also detectable, though in a lesser amount than $\mathrm{CD} 3+$ cells. (D) Large lymphatic vessel stained with D2-40.

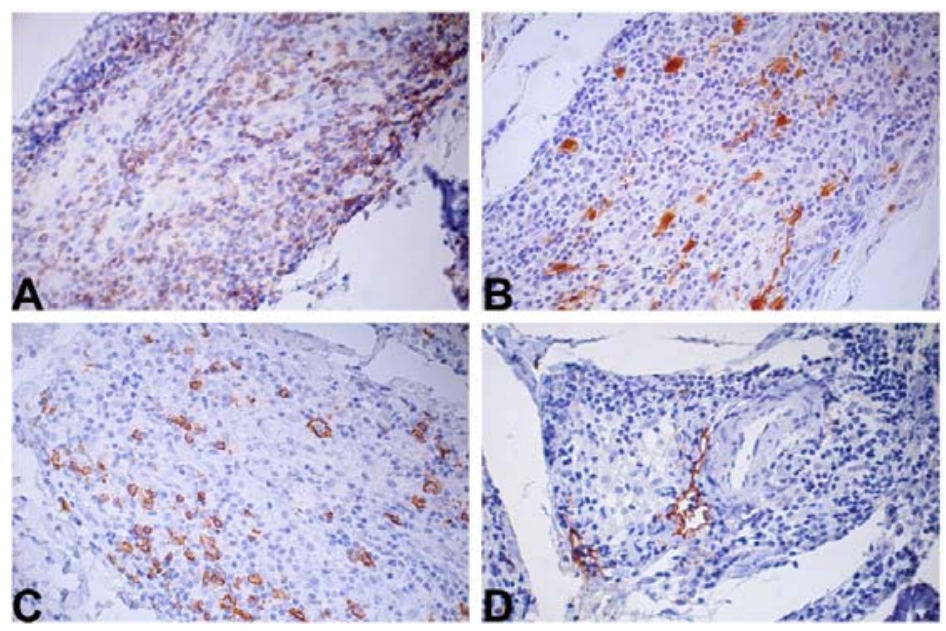

\section{Discussion}

OFG can encompass a broad of manifestations, including angular cheilitis, swelling of the cheek, full-thickness gingivitis, fissured tongue, mucosal ulcerations, linear oral ulceration, vertical fissures of the lips, and cobblestone or "basket of eggs" appearance of the buccal mucous membrane ${ }^{[7,9,10]}$. In this study, we provided a report of a case of OFG presenting as a recurrent swelling of the upper lip, mainly triggered by alcoholic beverages and soft drinks. The identification of the triggering factors, though sometimes difficult, is of great importance in avoiding recurrences ${ }^{[3]}$. This association of OFG with food intake has been reported, and several substances have been mentioned ${ }^{[10,12]}$. Interestingly, in a recent study of 119 OFG cases, $30 \%$ of patients with OFG reported a possible association with food, mainly chocolate, carbonated drinks, and beer ${ }^{[10]}$. The association with cinnamon was also reported ${ }^{[13]}$. 
Despite this association, the etiopathogenesis of OFG remains unclear. Genetics, allergy to food or dental materials, and infections have been mentioned as possible causes ${ }^{[9,12]}$. Of relevance, it seems that a delayed type hypersensitivity reaction takes place, incited by different antigens, which could reasonably be food components ${ }^{[9,11,12]}$.

It is still controversial whether OFG is a distinct entity or an oral presentation of Crohn's disease ${ }^{[7,12]}$. Crohn's disease is a chronic granulomatous disease that can affect any part of the gastrointestinal tract, from mouth to anus ${ }^{[4,5]}$, mainly in teenagers. A recent study suggested OFG to be a separate entity, however, patients with OFG onset in childhood would be more likely to develop Crohn's disease ${ }^{[8]}$. In the present case, the gastrointestinal affections presented were constipation and lactose intolerance, which can be related to many disorders. However, the patient is being followed-up because oral lesions can precede gastrointestinal tract lesions, representing the earliest manifestation of Crohn's disease ${ }^{[5,7-9]}$.

The patient also reported Hashimoto's thyroiditis, an autoimmune condition that leads to hypothyroidism ${ }^{[14]}$. Other authors also reported the occurrence of hypothyroidism in an OFG patient ${ }^{[5]}$. Similarly, McCartan et al. ${ }^{[10]}$ reported the occurrence of asthma, rhinitis, eczema, and allergies in patients with OFG. In addition, James et al. ${ }^{[15]}$ showed that $60 \%$ of a group of 75 patients with OFG presented clinical atopy. In the present case, the patient also reported allergy to antiinflammatory drugs. Therefore, considering that OFG could also have an immunological factor playing a role in the development of the disease, these associations should be better evaluated and reported. Few studies focused the interpretation of the inflammatory response in OFG. Dendritic cells (S-100+) are powerful antigen presenting cells, linking the innate and adaptive immune responses. $\mathrm{T}$ lymphocytes $(\mathrm{CD} 3+)$ are important cells of the adaptive immune response, and can have a cytotoxic CD8+ or helper CD4+ pattern. B lymphocytes (CD20+) are also components of the adaptive immune system, with the main function of antibodies' production.

In the present report, an intense and diffuse inflammatory infiltrate was seen in the connective tissue, immediately below the epithelium of the oral mucosa. It was mainly composed of S-100+ dendritic cells and CD3+ T lymphocytes, and these cells were found among keratinocytes as well. We can suppose that S-100+ cells are processing and presenting antigens, which in turns can be evoking the $\mathrm{T}$ lymphocytes. Further, the possible cytotoxic effects of CD8+ T lymphocytes may participate in the disorganization of the basal cells layer observed in the epithelium, as reported in lichen planus, an immunologically mediated disorder.

In the granulomas, S-100+ dendritic cells and CD3+ T lymphocytes were the major components as well. All these cells were diffusely distributed through the nodules. We can suggest that the cellular immune response is of greater relevance in the pathogenesis of the granulomatous nodules of OFG, and this is being incited by antigen presentation mediated by dendritic cells. In this line, it is reasonable to suggest that the presence of the large lymphatic vessels, evidenced by D2-40+ staining, seems to be associated with the persistent edema observed clinically.

Interestingly, CD20+ B lymphocytes were present in a lower amount in both arrangements (diffuse and granulomatous nodules). This corroborates with the knowledge that OFG may represent a delayed type hypersensitivity reaction, in which cell-mediated rather than antibody-mediated immune response takes place.

In accordance with our findings, Facchetti et al. ${ }^{[16]}$ reported a case showing that the lymphoid cells had the CD3+ profile, with a similar proportion of CD4+ and CD8+ cells. CD20+ cells were absent. Moreover, these authors showed that the diversity of the cell surface markers present on lesional lymphocytes were not different from that of the peripheral blood, suggesting that OFG is characterized by a random influx of inflammatory cells ${ }^{[16]}$.

Freysdottir et al. ${ }^{[17]}$ reported numerous CD3+ cells inside and outside granulomas, with both CD8+ and CD4+ cells. $\mathrm{CD} 20+$ cells were present in a lower proportion. These findings are in accordance with the present study. These authors also identified high indexes of IFN- $\gamma$ and IL-12, and low indexes of IL-4. They showed evidences that the immune response in OFG has a Th1 profile, similar to that of Crohn's disease ${ }^{[17]}$. 
Of relevance, the majority of treatments for OFG involve the use of corticosteroids, either topical, systemic, or intralesional. The treatment aims to lessen or even resolve oral lesions, and should be indicated in the presence of painful symptoms or aesthetic concerns ${ }^{[2,4,9]}$. In the present case, the labial swelling showed spontaneous regression, which is not common ${ }^{[9]}$. Importantly, the patient has already identified the triggering foods and thus she is avoiding such substances. This is relevant because recurrent episodes can lead to indurate and permanent swellings, resulting in significant cosmetic and functional damage ${ }^{[4,9]}$. Considering that corticosteroids act inhibiting the host immune response, we could speculate that the "therapeutic evidence" also points toward an important participation of the immunological basis in the development of OFG.

In conclusion, this paper reports a case of OFG in which dendritic cells and $\mathrm{T}$ lymphocytes were the major components of inflammatory infiltrate in both, diffuse distribution and granulomatous nodules. The disorganization of the epithelial basal cell layer was quite similar to that of lichen planus. Moreover, the patient also had Hashimoto's thyroiditis, which is an autoimmune disease. These evidences corroborate with the probable immunological pathway involving OFG. Although difficult, it is quite important to identify the triggering factors and to follow-up patients, considering that OFG can precede Crohn's disease, an important and debilitating condition. Based on our findings, OFG also seems to be part of a "frame" of immunological mediated disorders. The relevance of the pattern of distribution of the inflammatory cells (diffuse or granulomas) remains to be elucidated. Maybe this organization can be driven by the specific causative antigen or by the individual response to the type and / or intensity of the antigenic stimulation.

\section{Funding}

This study was supported in part by grants from FAPEMIG, CNPq, and CAPES, Brazil.

\section{References}

[1] Wiesenfeld D, Ferguson MM, Mitchell DN, MacDonald DG, Scully C, Cochran K, et al. Oro-facial granulomatosis--a clinical and pathological analysis. Q J Med. 1985 Jan; 54(213): 101-13. PMid: 3975343.

[2] Al Johani KA, Moles DR, Hodgson TA, Porter SR, Fedele S. Orofacial granulomatosis: clinical features and long-term outcome of therapy. J Am Acad Dermatol. 2010 Apr; 62(4): 611-20. PMid: 20137827. http://dx.doi.org/10.1016/j.jaad.2009.03.051

[3] Marcoval J, Viñas M, Bordas X, Jucglà A, Servitje O. Orofacial granulomatosis: clinical study of 20 patients. Oral Surg Oral Med Oral Pathol Oral Radiol. 2012 Apr; 113(4): e12-7. PMid: 22668438. http://dx.doi.org/10.1016/j.oooo.2011.10.011

[4] Tuxen AJ, Orchard D. Childhood and adolescent orofacial granulomatosis is strongly associated with Crohn's disease and responds to intralesional corticosteroids. Australas J Dermatol. 2010 May; 51(2): 124-7. PMid: 20546219. http://dx.doi.org/10.1111/j.1440-0960.2010.00627.x

[5] Jham BC, Meiller TF, King M, Scheper MA. A diffuse but subtle swelling of the upper lip. Oral Surg Oral Med Oral Pathol Oral Radiol Endod. 2008 Dec; 106(6): 773-7. PMid: 18755617. http://dx.doi.org/10.1016/j.tripleo.2008.06.020

[6] Miescher G. Übre essentielle granulomatöse mackrokeilie (cheilitis granulomatosa). Dermatol. 1945; 91(2-3): 57-85. http://dx.doi.org/10.1159/000255774

[7] Leão JC, Hodgson T, Scully C, Porter S. Review article: orofacial granulomatosis. Aliment Pharmacol Ther. 2004 Nov; 20(10): 1019-27. PMid: 15569103. http://dx.doi.org/10.1111/j.1365-2036.2004.02205.x

[8] Campbell H, Escudier M, Patel P, Nunes C, Elliott TR, Barnard K, et al. Distinguishing orofacial granulomatosis from crohn's disease: two separate disease entities? Inflamm Bowel Dis. 2011 Oct; 17(10): 2109-15. PMid: 21910172. http://dx.doi.org/10.1002/ibd.21599

[9] Grave B, McCullough M, Wiesenfeld D. Orofacial granulomatosis--a 20-year review. Oral Dis. 2009 Jan; 15(1): 46-51. PMid: 19076470. http://dx.doi.org/10.1111/j.1601-0825.2008.01500.x

[10] McCartan BE, Healy CM, McCreary CE, Flint SR, Rogers S, Toner ME. Characteristics of patients with orofacial granulomatosis. Oral Dis. 2011 Oct; 17(7): 696-704. PMid: 21749579. http://dx.doi.org/10.1111/j.1601-0825.2011.01826.x

[11] Lim SH, Stephens P, Cao QX, Coleman S, Thomas DW. Molecular analysis of T cell receptor beta variability in a patient with orofacial granulomatosis. Gut. 1997 May; 40(5): 683-6. PMid: 9203951.

[12] Tilakaratne WM, Freysdottir J, Fortune F. Orofacial granulomatosis: review on aetiology and pathogenesis. J Oral Pathol Med. 2008 Apr; 37(4): 191-5. PMid: 18321344. http://dx.doi.org/10.1111/j.1600-0714.2007.00591.x 
[13] Endo H, Rees TD. Cinnamon products as a possible etiologic factor in orofacial granulomatosis. Med Oral Patol Oral Cir Bucal. 2007 Oct; 12(6): E440-4. PMid: 17909510.

[14] Chistiakov DA. Immunogenetics of Hashimoto's thyroiditis. J Autoimmune Dis. 2005 Mar; 2(1): 1. PMid: 15762980. http://dx.doi.org/10.1186/1740-2557-2-1

[15] James J, Patton DW, Lewis CJ, Kirkwood EM, Ferguson MM. Oro-facial granulomatosis and clinical atopy. J Oral Med. 1986 Jan-Mar; 41(1): 29-30. PMid: 3457112.

[16] Facchetti F, Signorini S, Majorana A, Manganoni MA, Sapelli P, Imberti L. Non-specific influx of T-cell receptor alpha/beta and gamma/delta lymphocytes in mucosal biopsies from a patient with orofacial granulomatosis. J Oral Pathol Med. 2000 Nov; 29(10): 519-22. PMid: 11048969. http://dx.doi.org/10.1034/j.1600-0714.2000.291007.x

[17] Freysdottir J, Zhang S, Tilakaratne WM, Fortune F. Oral biopsies from patients with orofacial granulomatosis with histology resembling Crohn's disease have a prominent Th1 environment. Inflamm Bowel Dis. 2007 Apr; 13(4): 439-45. PMid: 17206709. http://dx.doi.org/10.1002/ibd.20023 